\title{
Analysis of a lift augmented hydrofoil for hydrokinetic turbines
}

\author{
Chica E ${ }^{1}$., Aguilar J., ${ }^{1}$ Rubio-Clemente A. ${ }^{2}$ \\ ${ }^{1}$ Departamento de Ingeniería Mecánica, Facultad de Ingeniería, Universidad de Antioquia UdeA, Calle 70, No. 52-21, \\ Medellín, Colombia. \\ ${ }^{2}$ Facultad de Ingeniería, Tecnológico de Antioquia-Institución Universitaria TdeA, Calle 78b, No. 72A-220, Medellín \\ (Colombia)
}

Phone/Fax number: +0057 2198553, e-mail: edwin.chica@udea.edu.co

\begin{abstract}
In the last years, increased attention has been given to hydrokinetic energy technologies due to these turbines represent an attractive technology for the harnessing of a huge untapped renewable energy potential in oceans, seas but also in rivers and canals. However, the low efficiency is an important barrier to its commercialization. The aim of this study is to present the selection of a multi-element hydrofoil that can enhance the hydrokinetic turbine performance. Therefore, in order to examine the influence of the type of airfoil used, as multi-element hydrofoil, on the blade performance, several studies using JavaFoil software were performed. The result indicates that hydrofoil multi-element Eppler 420 can provide high efficiency of the turbine because it has a higher relationship between the lift and drag coefficients $C_{L \max } / C_{D}$ (47.77) compared to the Selig S1223 profile (39.59) and other hydrofoils studied. Furthermore, computational fluid dynamics (CFD) was used to obtain the hydrodynamic characteristics of the hydrofoil Eppler 420 with and without flap. The CFD simulations were carried out using ANSYs-Fluent software. It was observed that there is an increase in the lift coefficient by $69.46 \%$ and $471.39 \%$ for the hydrofoil with flap and a chord length of $30 \%$, and a chord length of $70 \%$, respectively, under the analyzed conditions with respect to the hydrofoil without flap.
\end{abstract}

Keywords: multi-element blade, hydrokinetic turbine, hydrodynamic analysis, chord length, JavaFoil, 2D simulation

\section{Introduction}

Hydrokinetic turbines have been recently used as converters of kinetic energy of a water flow in mechanical energy without the use of large dams and reservoirs [1]. Afterwards, a generator is used to convert the mechanical energy into the electrical energy [1], [2], [3]. This feature makes them applicable to a larger number of sites [2], [3]. These technologies have become significant due to the increasing use of renewable energy sources with low environmental impact [2], [3]. The maximization of the power coefficient is fundamental in the hydrokinetic turbine design in order to improve the energy extracted from the water flow in rivers, and marine and tidal currents [4]. The power coefficient depends on the hydrodynamic turbine design and its value cannot be greater that a theoretical maximum value of 0.593 , called the Betz limit [2], [3]. For a typical hydrokinetic turbine with a fixed pitch angle, there is an optimum value of rotor tip-speed ration $(\lambda)$ that maximizes the power coefficient [1]-[4].
During the hydrodynamic turbine design, the selection of a proper hydrofoil shape and the calculation of the chord and twist angle distribution along the blade are crucial steps [4], [5]. The hydrofoil shape contributes to the generation of a lift coefficient by creating suction on the upper surface of the hydrofoil. In this process, a drag is also generated, which is not desirable when the maximization of the hydrokinetic turbine power output is desired. To get the maximum torque and power output from the hydrokinetic turbine, having a hydrofoil by which the high-lift and the high lift-to-drag ratio are generated is of special interest [6], [7], [8]. Therefore, the selection of a proper hydrofoil for the turbine is very important at initial stages of the design process. Depending on the area of the blade, the requirements can change to a large degree. In fact, the outer sections are optimized for high hydrodynamic performance, while the inner sections are designed to provide a low weight and structural integrity for the blade [5]-[8].

A common practice during the blade design of a hydrokinetic turbine is to use the available symmetric and non-symmetric airfoils designed and optimized for flight operation in different physical conditions [9], [10]. In general, these airfoils are not the optimal choice for blade design for hydrokinetic turbines operating at low Reynolds numbers [10], [11]. However, airfoils designed for low altitude gliders can be an option for blade design. Traditional airfoils, such as NACA airfoils developed by the National Advisory Committee of Aeronautics were designed to operate at high Reynolds number since they were mainly intended for full-scale aircraft [9]-[11].

At high Reynolds numbers, boundary layer transition takes place before laminar separation; thereby, avoiding thepeculiarities of low Reynolds number aerodynamics. In contrast, the behavior of the boundary layer is much different at low Reynolds numbers where laminar separation is predominant. Traditional airfoils used for the design of small horizontal axis wind turbines (HAWT), generally, exhibit poor performance at low Reynolds numbers because of laminar separation effects [9]. Therefore, optimum aerodynamic performance of small HAWTs is found through the use of airfoils designed for this subcritical flow regime; i.e., low Reynolds number airfoils [9], [10]. There are few airfoils have been designed for small HAWTS, which operate at a low Reynolds number, mainly they are NREL thick airfoil family (S822, S823). It is important to note that the profile S822 has been used for the design of hydrokinetic turbines [11]-[13]. On the other hand, the airfoil Selig (S1210, S1213 and S1223), originally designed to obtained high lift at high altitude for a drone, also can be used in the blade design of hydrokinetic turbines since these airfoils the high-lift has been reported at a 
low Reynolds number [11]-[13]. In the literature, there are other airfoils that have been demonstrated to improve the lift coefficient at low Reynolds number [14], [15].

Nowadays, multi-element hydrofoils or high-lift systems have been proposed as an alternative concept that may enhance the blade performance due to the lift coefficient is directly proportional to the mechanical power output. Therefore, an increase in the lift coefficient of a multi-element hydrofoil should improve the power coefficient of the turbine [16]-[18]. From the authors' knowledge, in the literature, there are few publications that consider multi-element hydrofoils in the design of hydrokinetic turbines [19]. Only, there is one work that studies the use of a double blade hydrofoil for generating the maximum lift [20]. Nevertheless, there are some numerical studies on multi-element airfoil configurations for wind turbines [21]-[25]. Additionally, in general terms, there are not studies optimizing the geometrical parameters of multi-element hydrofoils for obtaining a high lift-to-drag ratio for hydrokinetic turbine application.

To design an efficient multi-element hydrofoil, it is necessary to have a basic understanding on how and why the hydrofoil configuration can generate much higher lift coefficients compared to conventional single element hydrofoils. In general, hydrofoil characteristics include both hydrodynamic and structural requirements [6]-[8]. For the inner part of the blade, the structural requirements have higher priority that for the sections in the outer part of the blade [6]-[8]. In order to guarantee the required structural strength and stiffness, the hydrofoils at the root must have large values of moment of resistance; i.e., large values of thickness and sectional area [6][8].

In this paper, the focus is on the proper airfoil selection for multi-element hydrofoil design of a hydrokinetic turbine blade. Therefore, the performance of several airfoils was evaluated using JavaFoil software in order to select the best one in terms of the generation of the maximum lift and the highest lift-todrag ratio. The selected airfoil was studied using ANSYs-Fluent to obtain its hydrodynamic characteristics as a multi-element hydrofoil.

\section{Materials and methods}

\subsection{Multi-element hydrofoil configuration}

The geometrical configuration of the multi-element hydrofoil used in this study is shown in Figure 1. The purpose of a multielement hydrofoil is to increase the lift coefficient and delay the stall angle of a single hydrofoil [16]-[17]. The lift coefficient of a multi-element hydrofoil should improve the power coefficient of a hydrokinetic turbine.

The multi-element geometry used is conformed of two elements, including a main profile and a second element, which is called flap. The main element chord length, $c_{1}$, is defined as the length of a line joining the leading and the trailing edge of the main element. The flap chord length, $c_{2}$, is also defined in a similar manner. $\mathrm{C}$ is the system chord length and is defined as $c_{1}+c_{2}$ when both of the elements are set at an angle of attack of zero and placed end to end. To maintain this chord length at a fixed value, the flap was increased in size whenever the main element size was reduced to vary the main element to system chord ratio; thereby, defining a new hydrofoil in each case. The angle of attack, $\alpha$, is defined as the angle made by the main element chord with the ground plane, and is positive when its trailing edge is deflected upward with respect to its leading edge. The gap size, $d$, was defined as the vertical distance of the flap from the main element trailing edge while the overhang distance, $\mathrm{h}$, was defined as the horizontal distance of the flap leading edge from the main element trailing edge along the main element chord, as shown in Figure 1. In turn, the flap deflection angle, $\delta$, is the angle made by the flap chord relative to the main element chord, and is defined positive when the flap trailing edge is deflected upward.

The flap near the trailing edge induces a velocity over the main hydrofoil surface that leads to a rise in velocity on both the upper and the lower surface [17]-[18]. For the upper surface, this is beneficial because it raises the velocity at the trailing edge; thereby, reducing the severity of the adverse pressure gradient [17]-[19].

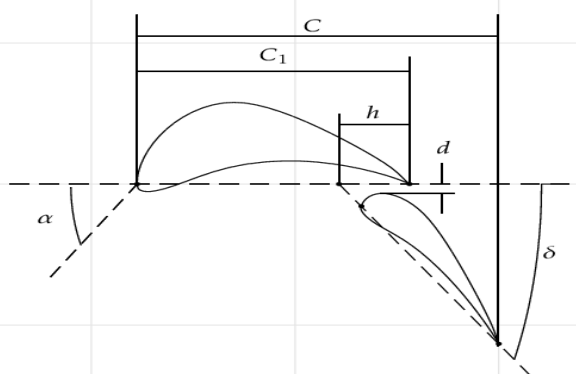

Figure 1. Schema of a multi-element hydrofoil.

Initially, for the design of the multi-element profile guidelines of previous studies done by Narsipur et. Al. in 2012 [20] have been followed (the second element is $30 \%$ of the main profile chord length $C_{1}$; the vertical space, $d$, is from 2 to $3 \%$ of $C_{1}$; the horizontal space, $\mathrm{h}$, between the edge of the drag of the main element and the leading edge of the second element is close to $5.3 \%$ of $C_{1}$, the deflection angle, $\delta$, is between 20 and $50^{\circ}$ and the angle of attack, $\alpha$, is between -5 and $20^{\circ}$.

\subsection{D JavaFoil analysis}

The JavaFoil code is a relatively simple program that combines a potential flow panel method and an integral boundary layer formulation for the analysis of the flow around airfoils or hydrofoil [26]. The analyses can be made for the desired $\alpha$ and Reynolds number. The main purpose of JavaFoil software is to determine the lift, drag and moment characteristics of airfoils or hydrofoils. The program will first calculate the distribution of the velocity on the surface of the airfoil. For this purpose, a potential flow analysis module which is based on a higher order panel method (linear varying vorticity distribution) is used. This local velocity and the local pressure are related by the Bernoulli equation. In order to find the lift and the pitching moment coefficient the distribution of the pressure can be integrated along the surface [26]. Next, JavaFoil code will calculate the behavior of the flow layer close to the airfoil surface (the boundary layer). The boundary layer analysis module (a so called integral method) steps along the upper and the lower surfaces of the airfoil, starting at the stagnation point [26]. It solves a set of differential equations to find the various boundary layer parameters. The boundary layer data is then used to calculate the drag of the airfoil from its properties at the trailing edge [26].

In this work, the airfoils analyzed as hydrofoils were S805, S822, Eppler 420, Eppler 421, Eppler 422, Eppler 423, Eppler 857, Wortmann FX 74-CL5-140, Wortmann FX 74-CL5-140 MOD, Douglas/Liebeck LA203A, Selig S1210, Selig S1223 and UI-1720.

For the hydrodynamic analysis of the airfoil like hydrofoil JavaFoil software was used. The software allows multi-element airfoil of hydrofoil design and import/export from/to .txt file having the coordinates list [26]. It is a very attractive tool to rapidly change the shape and visualize the results. In this work, the geometry was prepared with a CAD program which can write the $\mathrm{x}$-y coordinates to an ASCII file, then the complete set of coordinates including separator lines were pasted into the coordinate text area of the "Geometry card". After having created or imported a multi-element airfoil, the modification of its elements on the "Modify card" can be conducted. In the 
software, all coefficients are always given for a total chord length of 1.0. When the airfoil has been created, it is possible to calculate the lift and drag on "Polar card" after specification of the desired Reynolds number and angle of attack range. For each Reynolds number/angle of attack condition, JavaFoil code will first calculate the velocity distribution and then perform a boundary layer analysis. The resulting lift, drag and moment coefficients as well as location of transition and separation will be presented in graphs and tables.

For the profiles of the hydrokinetic turbine blades, small $\alpha$ are usually chosen where the lift coefficient is high and the drag coefficient is low [21]-[25]. These coefficients depend on the water velocity and, hence, on the Reynolds number, because when the viscosity forces are greater compared to the inertial forces, the effects of the friction are increased, affecting the velocities, the pressure gradient and the lift generated by the hydrodynamic profile [1]-[3], [27]-[28]. Therefore, for the

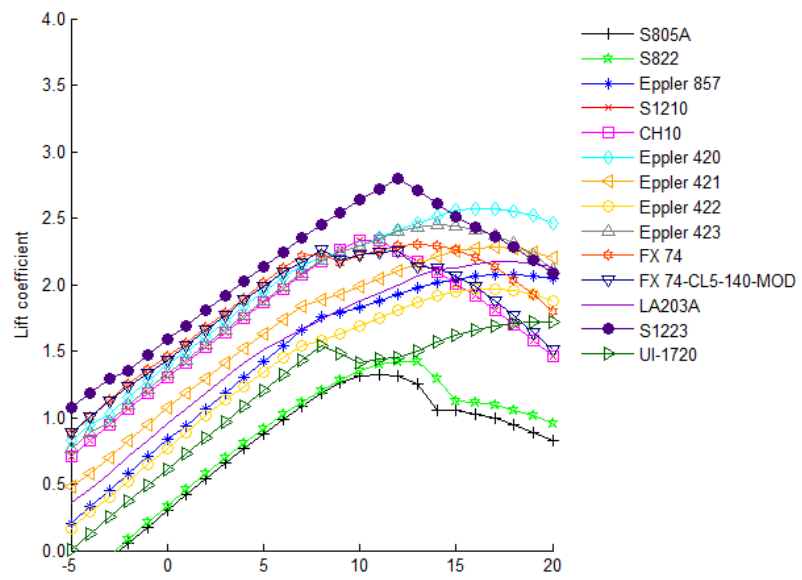

design of the blade of the hydrokinetic turbine, the profiles studied were selected to have a large lift-to-drag ratio. It also creates the need to select a profile with a considerable thickness to withstand the mechanical forces induced during the operation of the blade without falling into the failure of a profile that presents too much section, incurring an increase in the drag. The profiles were analyzed for a Reynolds number characteristic of hydrokinetic turbines equal to 750000 . The length of rope $C$ remained unitary in traditional profiles and multi-elements. The lift and drag coefficients were analyzed every $1^{\circ}$ in a wide range of $\alpha$. This procedure was followed for all the profiles analyzed. The comparison between the diagram of lift coefficient versus $\alpha$ for the airfoils used like hydrofoil obtained by numerical method are shown in the Figure 2 .

Figure 2. Lift coefficient $\left(\mathrm{C}_{\mathrm{L}}\right)$ versus the angle of attack $(\alpha)$ for several hydrofoils without (a) and with (b) flap obtained by numerical method

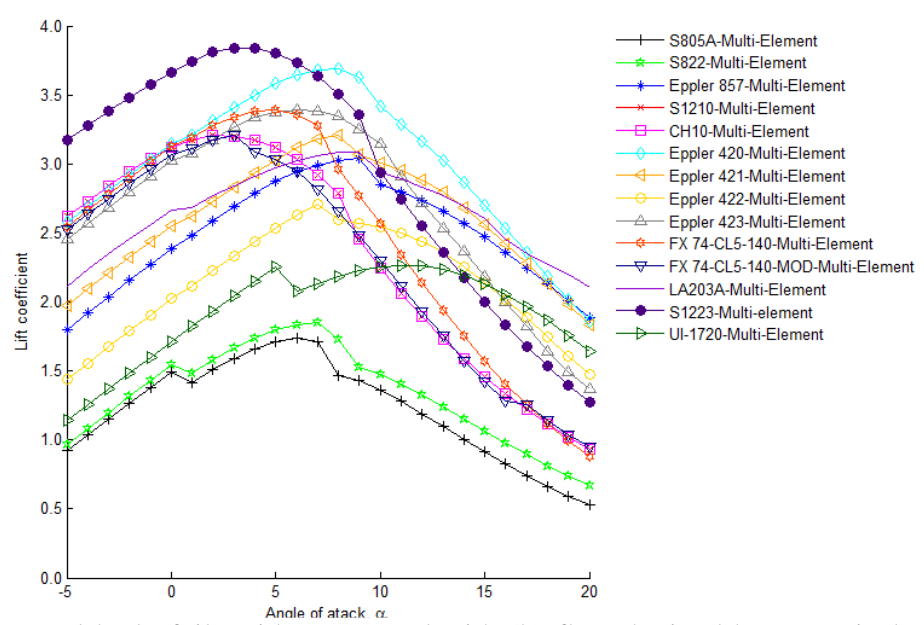

From the results, it was determined that the best profiles are Eppler 420 multi-element with $\alpha$ and deflection of the flap equal to $8^{\circ}$ and $30^{\circ}$, respectively, and Selig S1223 multielement with a $\alpha$ and deflection of the flap equal to $3^{\circ}$ and $10^{\circ}$, respectively. Selig S1223 multi-element has a lift coefficient $\mathrm{C}_{\text {Lmax }}$ (3.84) higher than Eppler 420 multi-element (3.69); however, Eppler profile has a higher relationship between the lift and drag coefficients $\mathrm{C}_{\mathrm{Lmax}} / \mathrm{C}_{\mathrm{D}}$ (47.77) compared to Selig profile (39.59), as illustrated in Figure 3. In addition, Eppler profile is thicker and capable of supporting higher hydrodynamic loads during its operation; therefore, this profile was chosen for the design of the blades of a $1 \mathrm{~kW}$ hydrokinetic turbine.

In general, the lift of the hydrofoils analyzed increases when $\alpha$ increases. Nonetheless, this increase is not infinite, since there is a point at which the slope of the curve begins to decrease, which implies that the profile loses its ability to lift. This phenomenon is known as loss of the hydrofoil lift, which is associated with the detachment of the fluid boundary layer. In the specific case of Eppler 420 multi-element hydrofoil, the $\alpha$ achieving the highest lift-to-drag ratio is equal to $8^{\circ}$; compared to the optimum $\alpha$ of $17^{\circ}$ found for the traditional hydrofoil Eppler 420 (i.e., the hydrofoil Eppler 420 without flap). Analyzing the whole set of profiles with and without multielements, it is observed that the optimum $\alpha$ for the multielement profiles are smaller than those ones achieved for traditional profiles without flap. In general, when $\alpha$ is small, the flow is similar to the ideal (non-viscous and irrotational). Under these situations, the interaction between the viscous and nonviscous field is weak. On the other hand, when $\alpha$ is high, a flow separation of the hydrodynamic profile begins to appear on the profile, which disturbs the non-viscous field, generating a strong interaction between it and the boundary layer, causing an early separation.

From Eppler 420 multi-element hydrofoil selected, the influence of the percentage of the length of the chord of the second element (flap) with respect to the length of the chord of the main element $C_{1}$ was determined. The percentage of the length of the chord of flap was varied between 40 and $90 \%$ to determine how the $C_{L \max }, C_{D}$ and $C_{L \max } / C_{D}$ of the multi-element hydrofoil changes. Table 1 shows the lift coefficients $\left(C_{L \max }\right)$ and drag $\left(C_{D}\right)$ change with respect to the chord length of the flap, $\mathrm{C}_{2}$. Results analysis show that the most appropriate length of the flap is $70 \%$ of the chord length for the main element.

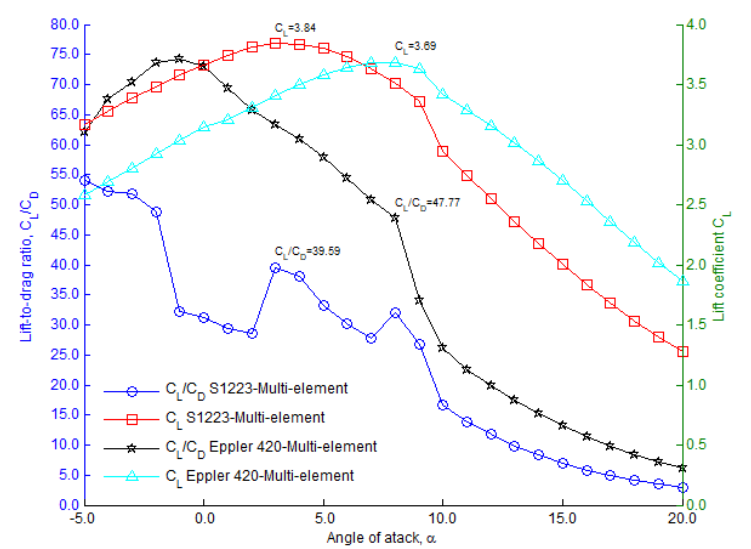

Figure 3. Comparison between Eppler 420 multi-element hydrofoil and Selig S1223 multi-element hydrofoil

\subsection{D CFD modeling and simulation}

Flow field around Eppler 420 hydrofoil with and without flap and the lift and drag coefficients were calculated by using CFD 
simulation. The steady-state governing the equations of continuity and momentum conservation were solved combined with the $k-\omega$ shear-stress transport (SST) turbulence model using the ANSYs-Fluent code [27], [28]. Three case studies were simulated (Figure 4). The first case study corresponded to Eppler 420 hydrofoil without flap and with a $\alpha$ of $17^{\circ}$. The second case study referred to Eppler 420 hydrofoil with flap, a $\alpha$ of $8^{\circ}$ and a chord length of the flap of $30 \%$ respect to the chord length of the main hydrofoil. The last case corresponded to Eppler 420 hydrofoil with flap, a $\alpha$ of $0^{\circ}$ and a chord length of the flap of $70 \%$ respect to the chord length of the main hydrofoil.

The grid structure used in the present study was depicted in Figure 4. It has a large influence on the accuracy of the analysis. Therefore, checking grid independence is necessary to eliminate the error arose because of coarseness of the grid. In the present study, a structured mesh in all the domain especially close to the hydrofoil was utilized in order to solve the viscous flow around it. The first step in the meshing process was to import the curves that make up the top and bottom, surfaces of the hydrofoil. The curves were created from a set of coordinate points for a chord length equal to 1 . The coordinate point files for hydrofoil were generated through an online application JavaFoil software. The grid used in this study had a CTopology in order to generate a completely structured mesh all over domain and avoiding generating unnecessary cells and enabling the inlet distance to the hydrofoil to remain the same. This mesh consists of a semicircle grid of radius equal to 5 times the chord length and a rectangular grid of length equal to 15 times the chord length. Once the geometry was created, the grid independence of the solution was tested using three different grid sizes for all the case studies.

The fluid was set to water with a density of $997 \mathrm{~kg} \mathrm{~m}^{-3}$ and a viscosity of $1.003 \mathrm{E}-3 \mathrm{~kg} \mathrm{~m}^{-1} \mathrm{~s}^{-1}$. An inlet velocity (V) equal to $1.5 \mathrm{~m} \mathrm{~s}^{-1}$ was established at the inlet of the computational domain. The turbulent boundary conditions at the inlet were a turbulent intensity of $2 \%$ and a turbulent viscosity ratio of 10 . The outlet of the domain was set as a pressure outlet with default boundary conditions. The hydrofoil was set as a no- slip wall so that a boundary layer would form over the surface.

Table 1. $\left(C_{L}\right)$ and $\left(C_{D}\right)$ coefficients of the multi-element hydrofoil Eppler 420 when the percentage of the chord length of the flap is varied

\begin{tabular}{|c|c|c|c|c|c|c|c|c|c|c|c|c|}
\hline \multirow[t]{2}{*}{$\alpha$} & \multicolumn{2}{|c|}{$40 \%$} & \multicolumn{2}{|c|}{$50 \%$} & \multicolumn{2}{|c|}{$60 \%$} & \multicolumn{2}{|c|}{$70 \%$} & \multicolumn{2}{|c|}{$80 \%$} & \multicolumn{2}{|c|}{$90 \%$} \\
\hline & $\mathrm{C}_{\mathrm{Lmax}}$ & $\mathrm{C}_{\mathrm{D}}$ & $\mathrm{C}_{\text {Lmax }}$ & $\mathrm{C}_{\mathrm{D}}$ & $\mathrm{C}_{\text {Lmax }}$ & $\mathrm{C}_{\mathrm{D}}$ & $\mathrm{C}_{\text {Lmax }}$ & $\mathrm{C}_{\mathrm{D}}$ & $\mathrm{C}_{\text {Lmax }}$ & $\mathrm{C}_{\mathrm{D}}$ & $\mathrm{C}_{\text {Lmax }}$ & $\mathrm{C}_{\mathrm{D}}$ \\
\hline-5 & 2.805 & 0.040 & 3.041 & 0.044 & 3.220 & 0.045 & 3.386 & 0.047 & 3.513 & 0.051 & 3.625 & 0.058 \\
\hline-4 & 2.919 & 0.041 & 3.154 & 0.043 & 3.332 & 0.046 & 3.497 & 0.051 & 3.623 & 0.058 & 3.730 & 0.063 \\
\hline-3 & 3.033 & 0.041 & 3.265 & 0.045 & 3.442 & 0.050 & 3.606 & 0.057 & 3.728 & 0.062 & 3.822 & 0.067 \\
\hline-2 & 3.145 & 0.042 & 3.375 & 0.049 & 3.551 & 0.055 & 3.708 & 0.061 & 3.822 & 0.066 & 3.883 & 0.071 \\
\hline-1 & 3.256 & 0.045 & 3.484 & 0.053 & 3.656 & 0.059 & 3.801 & 0.064 & 3.893 & 0.070 & 3.920 & 0.075 \\
\hline 0 & 3.365 & 0.049 & 3.588 & 0.057 & 3.753 & 0.062 & 3.869 & 0.069 & 3.937 & 0.074 & 3.928 & 0.080 \\
\hline 1 & 3.397 & 0.053 & 3.610 & 0.061 & 3.746 & 0.067 & 3.809 & 0.074 & 3.836 & 0.080 & 3.774 & 0.085 \\
\hline 2 & 3.494 & 0.056 & 3.690 & 0.064 & 3.796 & 0.071 & 3.815 & 0.078 & 3.814 & 0.084 & 3.709 & 0.092 \\
\hline 3 & 3.584 & 0.060 & 3.745 & 0.069 & 3.821 & 0.075 & 3.790 & 0.082 & 3.760 & 0.089 & 3.614 & 0.099 \\
\hline 4 & 3.666 & 0.063 & 3.772 & 0.074 & 3.819 & 0.080 & 3.735 & 0.088 & 3.676 & 0.096 & 3.491 & 0.109 \\
\hline 5 & 3.724 & 0.068 & 3.774 & 0.079 & 3.788 & 0.083 & 3.649 & 0.095 & 3.564 & 0.103 & 3.329 & 0.162 \\
\hline 6 & 3.756 & 0.072 & 3.746 & 0.086 & 3.726 & 0.090 & 3.522 & 0.147 & 3.409 & 0.165 & 3.163 & 0.207 \\
\hline 7 & 3.762 & 0.077 & 3.674 & 0.125 & 3.624 & 0.145 & 3.372 & 0.161 & 3.166 & 0.201 & 2.899 & 0.222 \\
\hline 8 & 3.741 & 0.083 & 3.572 & 0.135 & 3.489 & 0.157 & 3.103 & 0.197 & 2.969 & 0.217 & 2.712 & 0.239 \\
\hline 9 & 3.655 & 0.132 & 3.320 & 0.166 & 3.211 & 0.188 & 2.913 & 0.213 & 2.782 & 0.236 & 2.530 & 0.259 \\
\hline 10 & 3.403 & 0.154 & 3.153 & 0.181 & 3.033 & 0.204 & 2.726 & 0.231 & 2.599 & 0.255 & 2.295 & 0.287 \\
\hline 11 & 3.262 & 0.168 & 2.982 & 0.196 & 2.854 & 0.220 & 2.541 & 0.250 & 2.420 & 0.276 & 2.187 & 0.303 \\
\hline 12 & 3.115 & 0.182 & 2.807 & 0.212 & 2.672 & 0.237 & 2.361 & 0.270 & 2.248 & 0.299 & 1.969 & 0.335 \\
\hline 13 & 2.957 & 0.197 & 2.627 & 0.229 & 2.490 & 0.258 & 2.137 & 0.298 & 2.084 & 0.324 & 1.820 & 0.363 \\
\hline 14 & 2.789 & 0.213 & 2.447 & 0.249 & 2.314 & 0.278 & 1.972 & 0.322 & 1.929 & 0.351 & 1.681 & 0.393 \\
\hline 15 & 2.616 & 0.231 & 2.270 & 0.269 & 2.144 & 0.300 & 1.816 & 0.348 & 1.783 & 0.381 & 1.550 & 0.429 \\
\hline 16 & 2.442 & 0.249 & 2.100 & 0.289 & 1.979 & 0.326 & 1.669 & 0.377 & 1.646 & 0.415 & 1.426 & 0.467 \\
\hline 17 & 2.268 & 0.270 & 1.935 & 0.316 & 1.782 & 0.358 & 1.581 & 0.406 & 1.514 & 0.452 & 1.313 & 0.493 \\
\hline 18 & 2.099 & 0.292 & 1.780 & 0.342 & 1.637 & 0.388 & 1.450 & 0.441 & 1.342 & 0.485 & 1.213 & 0.525 \\
\hline 19 & 1.937 & 0.315 & 1.634 & 0.372 & 1.542 & 0.417 & 1.329 & 0.472 & 1.237 & 0.517 & 1.118 & 0.555 \\
\hline 20 & 1.783 & 0.342 & 1.495 & 0.404 & 1.410 & 0.451 & 1.223 & 0.502 & 1.138 & 0.552 & 1.029 & 0.595 \\
\hline $\max / C_{D}$ & \multicolumn{2}{|c|}{48.991} & \multicolumn{2}{|c|}{47.526} & \multicolumn{2}{|c|}{50.683} & \multicolumn{2}{|c|}{56.293} & \multicolumn{2}{|c|}{53.074} & \multicolumn{2}{|c|}{49.285} \\
\hline
\end{tabular}
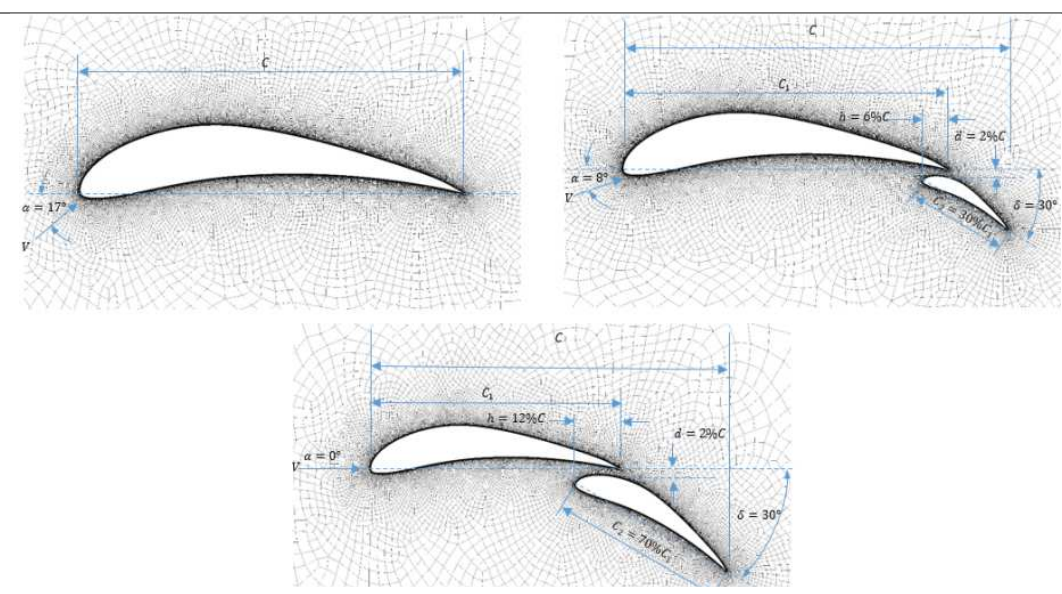
Figure 4. Case studies. a) Case 1: Eppler 420 hydrofoil without flap with $\alpha$ of $17^{\circ}$. b) Case 2: Eppler 420 hydrofoil with flap and with $\alpha$ of $8^{\circ}$. Case 3: Eppler 420 hydrofoil with flap and with $\alpha$ of $0^{\circ}$.

\section{Results}

The lift and drag coefficients were computed to understand the effect of the flap and the length of the second element on the multi-element hydrofoil system performance. Figure 5 shows the lift coefficient and lift-to-drag ratio for hydrofoil Eppler 420 with and without flap. It can be seen that for the hydrofoils with flap, both the lift coefficient and the lift-to-drag ratio increases. It can also be seen that the lift and lift-to-drag ratio increases when the chord length of the second element, or flap, is equal to $70 \%$. It is observed that there is an increase in the lift coefficient by $69.46 \%$ and $471.39 \%$ for the hydrofoil with flap (chord length of 30\%) and for the hydrofoil with flap (chord length of 70\%), respectively, under the analyzed conditions respect to the results obtained for the hydrofoil without flap.

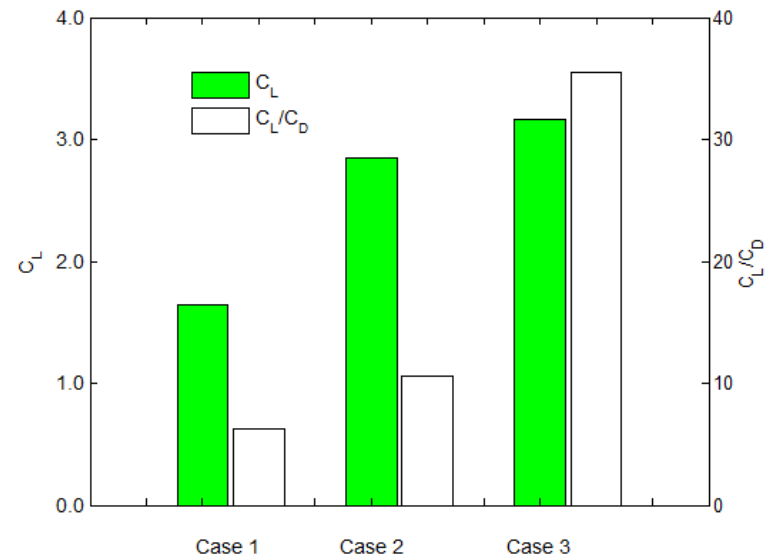

Figure 5. Comparison of the lift coefficient $\left(\mathrm{C}_{\mathrm{L}}\right)$ and the lift-todrag ratio $\left(\mathrm{C}_{\mathrm{L}} / \mathrm{C}_{\mathrm{D}}\right)$ for the cases studies
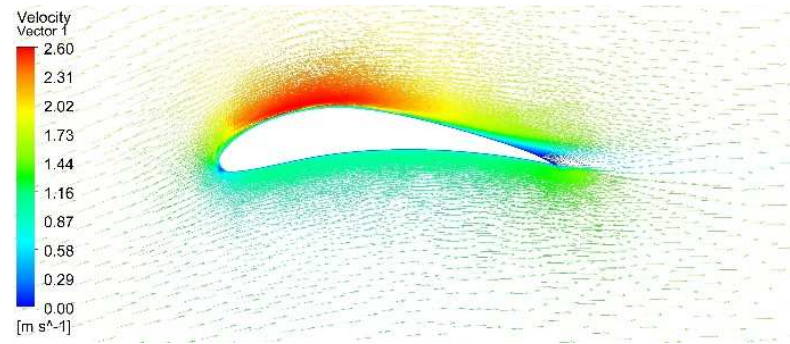

a) Case study 1
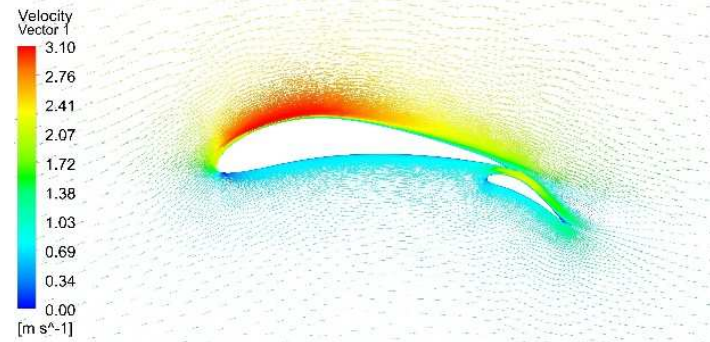

b) Case study 2
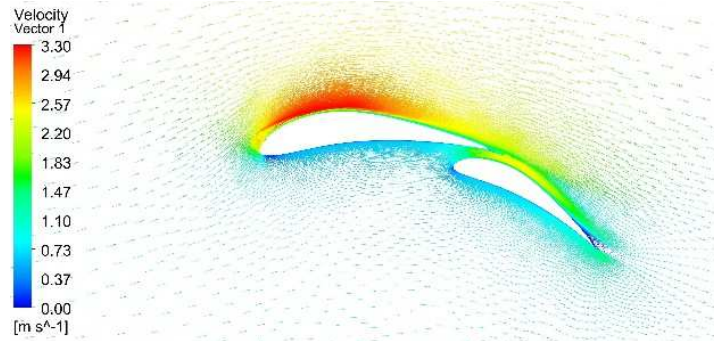

Case study 3
It is important to note that the behavior of hydrofoils coincide with those ones obtained with Javafoil code, However, the numerical results obtained with Fluent are not in agreement with the numerical results obtained with JavaFoil software. One of the reasons explaining this aspect is ascribed to Javafoil code, which does not model laminar separation bubbles and flow separation. Therefore, the results achieved will be inaccurate if such effects occur. Since flow separation occurs at stall, the analysis beyond the stall will give an inaccurate result. Commonly, flow separation results in a loss of the lift, and an increase of the drag, as well as pressure recovery reduction. On the other hand, JavaFoil software tends to show a more positive lift coefficient compared to the numerical results from ANSYsFluent software.

Pressure and velocity contours in the flow field around the cases studies for the Eppler 420 hydrofoil are depicted in Figure 6. An increase in pressure can be observed at the stagnation point (stagnation point is the point in the flow field where the local velocity of fluid is zero) [21]-[26]. In multi-element hydrofoil, the stagnation point is near the trailing edge of the flap. With the flap, the flow separation was reduced. On the other hand, due to the velocity increase, pressure diminishes in the upper region and increases in the lower region. The case study 3 shows advantages in comparison of case study 1 and 2 , since the geometric configuration increases the lift and the hydrodynamic efficiency. The forces of pressure acting on the hydrofoil are higher when the second element chord length is equal to $70 \%$ of the main element chord length.

On the other hands, the hydrodynamic performance of multielement hydrofoil systems could be highly dependent on $\delta, \mathrm{h}$ and $d$, therefore, futures research on the performance of the hydrofoil under different combinations of these geometrical parameters should be done.
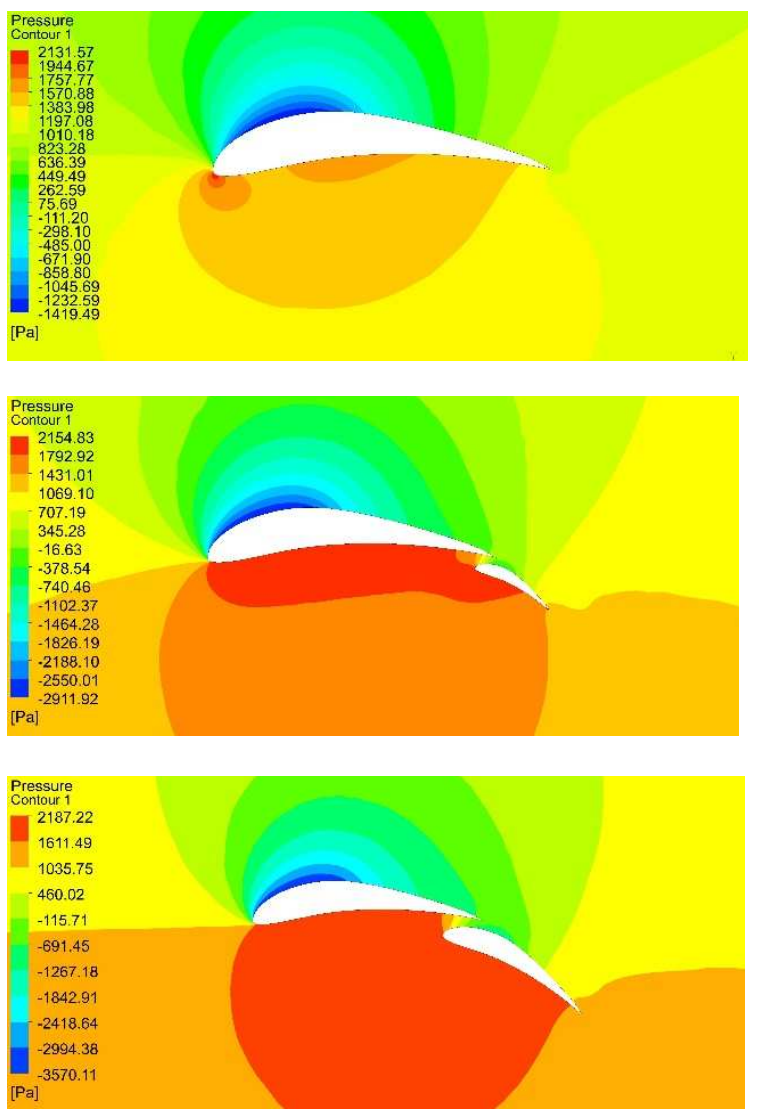
Figure 6. Eppler 420 velocity and pressure contours a) Case 1: Eppler 420 hydrofoil without flap and with $\alpha$ of $17^{\circ}$. b) Case 2: Eppler 420 hydrofoil with flap and $\alpha$ of $8^{\circ}$. Case 3: Eppler 420 hydrofoil with flap and $\alpha$ of $0^{\circ}$.

\section{Conclusion}

The hydrofoil shape contributes to the generation of a lift coefficient by creating suction on the upper surface of the airfoil or hydrofoil. During this process, a drag is also being generated, which is not desirable for the maximum power output of the hydrokinetic turbine. To get the maximum torque and power output from the hydrokinetic turbine, it is important to have a hydrofoil which will generate the high-lift and the high lift-todrag ratio. Selection of a proper airfoil to be used as for the hydrokinetic turbine is crucial at initial stages of the design process. Multi-element hydrofoils used in hydrokinetic turbine blades are promising options in the increase of the turbine performance. Therefore, numerical simulations were carried out in JavaFoil software aiming at selecting a multi-element hydrofoil for the design of hydrokinetic turbine blade. The lift and drag coefficients were computed to understand the effect of the flap on the multi-element hydrofoil system performance. The results of JavaFoil software indicate that the hydrofoil Eppler 420 multi-element with the chord length of the second element equal to $30 \%$ has a high relationship between the lift and drag coefficients $C_{\text {Lmax }} / C_{D}$ (47.77) compared to Selig S1223 profile (39.59) and other studied hydrofoils.

On the other hand, CFD simulation of the flow around a Eppler 420 multi-element hydrofoil showed a remarkable increase in the lift coefficient in comparison with Eppler 420 hydrofoil without flap. Eppler 420 multi-element hydrofoil with chord length of the second element equal to $70 \%$ has the highest lift and lift-to-drag ratio at a $\alpha$ equal to $0^{\circ}$. Therefore, in order to achieve the maximum hydrodynamic efficiency, the selection of this profile is required for the design of the blade of a hydrokinetic turbine.

\section{Acknowledgement}

The authors gratefully acknowledge the financial support provided by the Colombia Scientific Program within the framework of the call Ecosistema Científico (Contract No. FP44842- 218-2018).

\section{References}

[1] Anyi M. and Kirke B. Evaluation of small axial ow hydrokinetic turbines for remote communities. Energy for Sustainable Development, vol. 14 (2), pp.110-116, 2010.

[2] Kumar D. and Sarkar S. A review on the technology, performance, design optimization, reliability, techno-economics and environmental impacts of hydrokinetic energy conversion systems. Renewable and Sustainable Energy Reviews, vol. 58, pp. 796-813, 2016.

[3] Vermaak HJ., Kusakana K. and Koko SK. Status of microhydrokinetic river technology in rural applications: A review of literature. Renewable and Sustainable Energy Reviews, vol. 29, pp. 625-633, 2014.

[4] Kolekar N., Mukherji S., and Banerjee A. Numerical Modeling and Optimization of Hydrokinetic Turbine. ASME. Energy Sustainability, ASME 2011 5th International Conference on Energy Sustainability, Parts A, B, and C():1211-1218.

[5] Grégory S., Payne, Stallard T., and Martinez R. Design and manufacture of a bed supported tidal turbine model for blade and shaft load measurement in turbulent flow and waves. Renewable Energy, vol 107, pp. 312-326, 2017.

[6]. Chica E., Pérez F., Rubio-Clemente R., and Agudelo S. Design of a hydrokinetic turbine. WIT Transactions on Ecology and The Environment. Wessex Institute of Technology, vol. 195, pp 137-148, 2015.

[7]. Chica E., Pérez F., and Rubio-Clemente A. Rotor structural design of a hydrokinetic turbine. International Journal of Applied Engineering Research, vol. 11(4), pp 2890-2897, 2016.
[8] Chica E. and Rubio-Clemente A. Design of Zero Head Turbines for Power Generation, Renewable Hydropower Technologies Basel I. Ismail, IntechOpen, DOI: 10.5772/66907. Available from: https://www.intechopen.com/books/renewablehydropower-technologies/design-of-zero-head-turbines-forpower-generation. July 26th 2017.

[9] Prasad C. and Søren RK. Simulation of flow over doubleelement airfoil and wind tunnel test for use in vertical axis wind turbine. Journal of Physics: Conference Series, vol. 524, 012009, 2014.

[10] Giguere P. and Selig MS. Low Reynolds number airfoils for small horizontal axis wind turbines. Wind Engineering, vol. 21(6), pp. 367-380, 1997.

[11] Ronit K. and Singh M. Rafiuddin Ahmed, Mohammad Asid Zullah, Young-Ho Lee. Design of a low Reynolds number airfoil for small horizontal axis wind turbines. Renewable Energy, vol 42, pp. 66-76, 2012.

[12] Jai N., Goundar M., Rafiuddin A. and Young-Ho L. Numerical and experimental studies on hydrofoils for marine current turbines. Renewable Energy, vol 42, pp. 173-179, 2012. [13] Oller SA. and Nallim L.The usability of the Selig S1223 profile airfoil as a high lift hydrofoil for hydrokinetic application. Journal of Applied Fluid Mechanics (JAFM), vol 9 (3), pp. 1-7, 2016.

[14] Ragheb A. and Selig M. Chapter 11 - Multielement Airfoils for Wind Turbines. Editor(s): Trevor M. Letcher, Wind Energy Engineering, Academic Press, pp 203-219, 2017.

[15] Morgado J., Vizinho R., Silvestr M. and Páscoa J. XFOIL vs CFD performance predictions for high lift low Reynolds number airfoils. Aerospace Science and Technology, vol. 52, pp. 207-214, 2016.

[16] Smith A. Hight Lift Aerodynamics, Journal of Aircraft, vol. 12 (6), 501-530, 1975.

[17] Bah E., Sankar L. and Jagoda J. Investigation on the Use of Multi-Element Airfoils for Improving Vertical Axis Wind Turbine Performance, 51st AIAA Aerospace Sciences Meeting Including The New Horizons Forum and Aerospace Exposition. 2013.

[18] Lew P. Multi-element wind turbine airfoils and wind turbines incorporating the same, United States Patent office, Patent no. US 2011/0255972 A1, 2011.

[19] Yavuz T., Birol K.; Hursit A. and Özgur E. Performance Analysis of a Hydrofoil with and without Leading Edge Slat. 10th International Conference on Machine Learning and Applications and Workshops, 2011.

[20] Yavuz T. and Koç E. Performance analysis of double blade airfoil for hydrokinetic turbine applications. Energy Conversion and Management, vol. 63, pp. 95-100, 2012.

[21] Narsipur S., Pomeroy B. and Selig M. CFD Analysis of Multielement Airfoils for Wind Turbines. 30th AIAA Applied Aerodynamics Conference 25-28 June, New Orleans, Louisiana. pp. 2012-2781, 2012.

[22] Zahle F., Gaunaa M., Sørensen N. and Bak C. Design and Wind Tunnel Testing of a Thick, MultiElement High-Lift Airfoil. In Proceedings of EWEA 2012 - European Wind Energy Conference \& Exhibition European Wind Energy Association (EWEA), 2012.

[23] Ragheb A. and Selig M. Multi-Element Airfoil Configurations for Wind Turbines. 29th AIAA Applied Aerodynamics Conference 27 - 30 June, Honolulu, Hawaii. AIAA 2011-3971, 2011.

[24] Sood I. Multi-Element Blade Design for MW-Scale Wind Turbines, in 17th AIAA Aviation Technology, Integration, and Operations Conference, 2017.

[25] Ragheb A. and Selig M. Multielement Airfoils for Wind Turbines. in Wind Energy Engineering pp. 203-219, 2017.

[26] Hepperle M. JAVAFOIL User's Guide. 2017. 
https://www.mh-

aerotools.de/airfoils/java/JavaFoil\%20Users\%20Guide.pdf . Available on line 22 october 2018.

[27] Liangyu X., Baglietto E. and Brizzolara S. Extending the applicability of RANS turbulence closures to the simulation of transitional flow around hydrofoils at low Reynolds number. Ocean Engineering. vol 164, pp. 1-12, 2018.

[28] Dajani S., Shehadeh M., Saqr KM., Elbatran AH., Hart N., Soliman A. and Cheshire D. Numerical Study for a Marine Current Turbine Blade Performance under Varying Angle of Attack. Energy Procedia, vol. 119, pp. 898-909, 2017. 